\title{
FGF signaling induces mesoderm in members of Spiralia
}

\author{
Carmen Andrikou*1,2 and Andreas Hejnol ${ }^{1,2}$
}

${ }^{1}$ University of Bergen, Department of Biological Sciences, Thormøhlensgate 55, 5006 Bergen, Norway

${ }^{2}$ Sars International Centre for Marine Molecular Biology, University of Bergen, Thormøhlensgate 55, 5006 Bergen, Norway

*Corresponding author: carmen.andrikou@uib.no

\begin{abstract}
FGF signaling is involved in mesoderm induction in deuterostomes, but not in flies and nematodes, where it has a role in mesoderm patterning and migration. However, comparable studies in other protostomic taxa are missing in order to decipher whether this mesoderm-inducing function of FGF extends beyond the lineage of deuterostomes. Here, we investigated the role of FGF signaling during mesoderm development in three species of lophophorates, a clade within the protostome group Spiralia. Our gene expression analyses show that the molecular patterning of mesoderm development is overall conserved between brachiopods and phoronids, but the spatial and temporal recruitment of transcription factors differs significantly. Moreover, inhibitor experiments demonstrate that FGF signaling is involved in mesoderm formation, morphogenetic movements of gastrulation and posterior axial elongation. Our findings suggest that the inductive role of FGF in mesoderm possibly predates the origin of deuterostomes.
\end{abstract}

Keywords: phoronid, brachiopod, development, axial elongation, gastrulation, SU5402, fibroblast growth factor 


\section{Introduction}

Mesoderm is an embryonic germ layer of bilaterians that gives rise to tissues residing between the ectoderm and endoderm (Hyman, 1951; Ruppert, 1991). The way mesoderm is formed differs between embryos. For instance, deuterostomes generally form mesoderm by outpouchings of their invaginating endoderm (archenteron), a mechanism named enterocoely, which is not observed in protostomes, except for the Chaetognatha (Hertwig; Kapp, 2000; Matus et al., 2006) and Brachiopoda (Conklin, 1902; Kowalevsky, 1874; Plenk, 1913). In the remaining protostomes mesoderm originates from one or more precursor cells that are internalized during gastrulation; spiralian species can have an endodermal (e.g. the micromere 4d) and an ectodermal source (e.g. micromeres from the animal pole/anterior end of the blastopore) of mesoderm (summarized in Henry and Martindale, 1999; Kozin and Kostyuchenko, 2016; Lambert, 2008; Lyons and Henry, 2014), and ecdysozoan mesoderm originates either from internalization of vegetal endomesodermal cells (Martin-Duran and Hejnol, 2015; Sulston et al., 1983), or cells of the blastoderm (Eriksson and Tait, 2012; Hartenstein et al., 1985). Despite the differences in the embryological origin and developmental mechanisms, the molecular patterning of mesoderm induction and differentiation into various organs shares similarities between bilaterians (Amin et al., 2009; Amin et al., 2010; Andrikou et al., 2013; Chiodin et al., 2013; Fritzenwanker et al., 2014; Grifone et al., 2005; Harfe et al., 1998; Hinman and Degnan, 2002; Imai et al., 2004; Kozin et al., 2016; Kozmik et al., 2007; Mahlapuu et al., 2001; Mankoo et al., 1999; Materna et al., 2013; Nederbragt et al., 2002; Osborne et al., 2018; Passamaneck et al., 2015; Perry et al., 2015; Rudnicki et al., 1993; Sandmann et al., 2007; Schubert et al., 2003; Shimeld et al., 2010; Zaffran et al., 2001). This molecular conservation has been commonly used as an argument for the homology of this germ layer (Burton, 2008; Lartillot et al., 2002; Martindale et al., 2004; Seipel and Schmid, 2005; Technau and Scholz, 2003). Apart of shared sets of transcriptions factors, conserved signaling cascades are also involved in different steps of mesoderm development such as FGF, Notch and BMP (Good et al., 2004; Itoh and Ornitz, 2004; Sweet et al., 1999; Wijesena et al., 2017; Winnier et al., 1995). Among the aforementioned, FGF signaling is of particular interest due to its proposed ancestral role in mesoderm induction in deuterostomes (Fan et al., 2018; Green et al., 2013). 
Functional studies have demonstrated that this signal is required for posterior mesoderm formation in vertebrates (Amaya et al., 1993; Draper et al., 2003; Fletcher et al., 2006; Fletcher and Harland, 2008; Yamaguchi et al., 1994), anterior mesoderm formation in cephalochordates (Bertrand et al., 2011), mesenchyme induction and formation of notochord, TVC and tail muscle in tunicates (Davidson et al., 2006; Imai et al., 2002; Kim and Nishida, 2001; Yasuo and Hudson, 2007), mesoderm induction in hemichordates (Fan et al., 2018; Green et al., 2013) and myoblast formation in sea urchins (Andrikou et al., 2015). Outside deuterostomes, however, studies addressing the role of FGF in mesoderm development are scarce. The only available data among protostome taxa concerns the two well-studied ecdysozoans Drosophila melanogaster and Caenorhabditis elegans, in which FGF is involved in mesoderm patterning and migration but not in induction (Beiman et al., 1996; Burdine et al., 1998; DeVore et al., 1995; Kadam et al., 2009; Lo et al., 2008; McMahon et al., 2010; Photos et al., 2006; Stathopoulos et al., 2004; Sun and Stathopoulos, 2018; Wilson et al., 2005). A question therefore emerges as to whether the mesoderm-inducing role of FGF originated in deuterostomes, or predated deuterostomes and got lost in the lineage of ecdysozoans (Fig. 1a). To gain insight into the ancestral role of FGF signaling for mesoderm development, data from other protostomes and, in particular, members of the Spiralia, are therefore needed.

Lophophorates belong to the lineage of Spiralia, comprised of Bryozoa, Brachiopoda and Phoronida (Kocot et al., 2017; Laumer et al., 2019) (Fig. 1a). These animals exhibit "deuterostome-like" features in their development, such as radial cleavage and enterocoely (Zimmer, 1997). We used two brachiopod species, the rhynchonelliform Terebratalia transversa and the craniiform Novocrania anomala, and one phoronid species, Phoronopsis harmeri (Fig. 1b), which show profound differences in mesoderm development such as the time and site of mesoderm emergence, the direction of mesoderm migration and the degree of mesoderm compartmentalization. In particular, in T. transversa mesoderm originates at the blastula stage, while the mesoderm of $N$. anomala and Ph. harmeri forms at the gastrula stage (twist positive cells) (Andrikou et al., 2019; Martín-Durán et al., 2016; Passamaneck et al., 2015). In addition, in T. transversa and Ph. harmeri mesoderm proliferates in an anterior-to-posterior direction, but in N. anomala it follows a posterior-to-anterior direction (Andrikou et al., 2019; Freeman, 1993; Freeman, 2000; Freeman, 2003; Martín-Durán et al., 2016; Nielsen, 1991; Passamaneck et al., 2015; Rattenbury, 1954; Temereva and Malakhov, 2007). 
Finally, in T. transversa larvae, mesoderm consists of an anterior domain in the apical lobe, an umbrella-like domain in the mantle lobe that projects to four coelomic sacs with chaetae bundles, and a posterior domain in the pedicle lobe (Freeman, 2003; Martín-Durán et al., 2016; Passamaneck et al., 2015; Vellutini and Hejnol, 2016); in N. anomala mesoderm compartmentalizes in four pairs of coelomic sacs, with the three posterior ones to project into chaetae bundles (Freeman, 2000; Martín-Durán et al., 2016; Nielsen, 1991; Vellutini and Hejnol, 2016), and in Ph. harmeri mesoderm can be distinguished between an anterior domain in the pre-oral lobe with projecting ventrolateral muscle bands, and a posterior domain that emerges at the larva stage (Andrikou et al., 2019; Rattenbury, 1954; Temereva and Malakhov, 2007) (Figure 1b). We investigated and compared the molecular mechanisms of mesoderm development in these three species, with an emphasis on the role of FGF. Despite our observed differences in the presumptive mesodermal gene regulatory networks (GRN), our results indicate a conservation of the inductive role of FGF signaling pathway in mesoderm with deuterostomes.

a

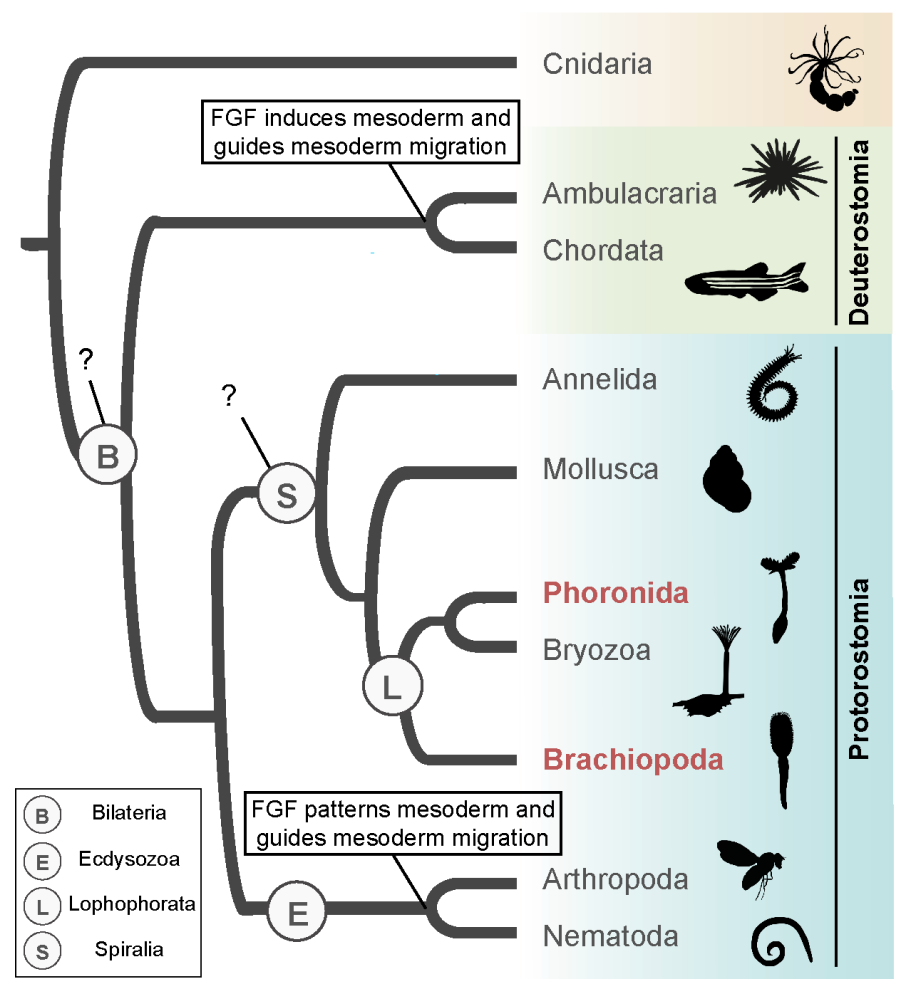

b
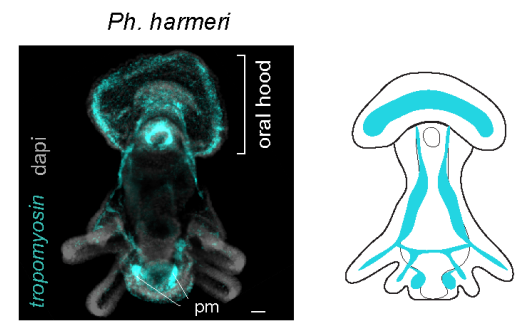

T. transversa
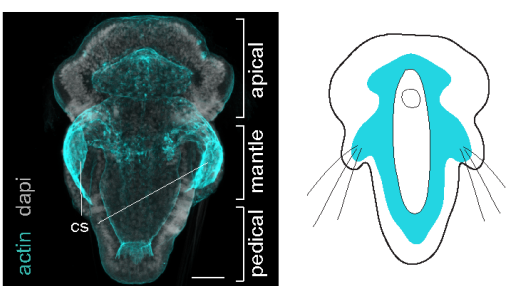

N. anomala
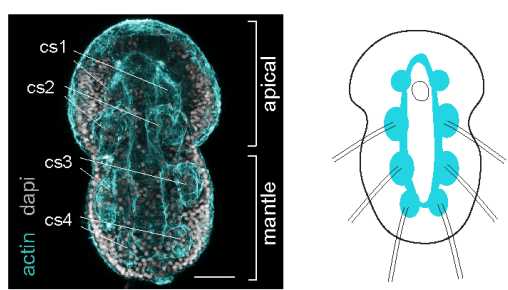

Fig. 1. The distinct roles of FGF signaling in mesoderm development among bilaterians. (a) FGF signaling plays pivotal roles in mesoderm formation and migration in deuterostomes; however, in protostomes the information is restricted in members of ecdysozoans, where it acts in mesoderm patterning and migration. Animal illustrations are taken from phylopic.org (CC BY 
3.0). (b) Mesoderm morphology in larvae of three representative lophophorate species; the brachiopods Terebratalia transversa and Novocrania anomala, and the phoronid Phoronopsis harmeri. Next to the images, schematic representations are shown. Drawings are not up to scale. In brachiopods mesoderm is stained by immunohistochemistry against actin and in Ph. harmeri mesoderm is stained by tropomyosin gene expression. Every fluorescent image is a full projection of merged confocal stacks and nuclei are stained with DAPI. Anterior to the top. cs, coelomic sac; pm, posterior mesoderm. Scale bar: 20 um.

\section{Results}

The spatiotemporal mesodermal patterning differs between $N$. anomala, $T$. transversa and Ph. harmeri

To understand whether the developmental and morphological variations of mesoderm formation between these three species are associated to differences in molecular patterning, we revealed the expression of the transcription factors twist, mox, six 1/2, eya, mef2, dachs, paraxis, foxc, mprx, myod, limpet, foxf and $n k 1$ in $N$. anomala and Ph. harmeri (Figs 2, $3 \mathrm{~S} 1$ and S2). The mesodermal expression of these genes has been previously described in T. transversa (Passamaneck et al., 2015). All genes, with the exception of $n k l$ (in $N$. anomala) (Fig. S2a), showed mesodermal expression. The earliest mesodermal marker is twist (Andrikou et al., 2019; Martín-Durán et al., 2016), whose expression initiates at the early gastrula stage and demarcates the entire mesoderm in both species (Figs 2A2-3 and 3A2-3), indicating that mesoderm originates before its morphological separation from endoderm. Mox, six $1 / 2$ and eya, genes commonly involved in mesoderm patterning, are expressed shortly after (Figs 2B2-3, 2C2-3, 2D2-3 and 3B2-3, 3C2-3, 3D2-3). Transcripts of transcription factors often associated with muscle development, such as myod, limpet (only in N. anomala), foxf (Martín-Durán et al., 2016) and the terminal differentiation gene tropomyosin, are only detected at the late gastrula stage (Figs 2H4-5, 2I4-5, 2J4-5, 2K4-5 and 3J4-5, 3K4-5) in both organisms, correlating with the formation of musculature (Altenburger and Wanninger, 2010; Temereva and Tsitrin, 2013).

However, when comparing these results with data from T. transversa (Martín-Durán et al., 2016; Passamaneck et al., 2015), the onset of expression of a number of orthologs varies (Fig. S3). For instance, in T. transversa the expression of mox and eya only starts at the late gastrula stage (Passamaneck et al., 2015), although mesoderm (twist positive cells) is already present since the blastula stage (Martín-Durán et al., 2016). Also, mef2 shows an early mesodermal expression in N. anomala (Fig. 2E2-3), but in T. transversa 
(Passamaneck et al., 2015) and Ph. harmeri (Fig. 3E4-5) this gene is not activated before the late gastrula stage. A second important difference concerns the spatial patterning of the different subpopulations of mesoderm (Fig. S3). Twist is expressed in both anterior and posterior mesodermal subsets in Ph. harmeri (Fig. 3A2-9), in $N$. anomala it is expressed in most of the mesoderm but acquires a stronger expression at the posterior one (cs4) (Fig. 2A6-7), and in T. transversa twist expression confines in the anterior mesoderm (Passamaneck et al., 2015). The expression of six 1/2 and myod is excluded from the posterior (cs4) mesoderm in N. anomala (Fig. 2C6-7, H6-7), while in $T$. transversa these genes are expressed in both the anterior (apical) and posterior (pedicle) mesoderm (Passamaneck et al., 2015). In Ph. harmeri sixl/2 and myod are restricted in the anterior (Fig. 3C2-5) and posterior mesoderm, respectively (Figs 3I89 and S2b). Moreover, mprx is solely expressed in the mantle mesoderm of $T$. transversa (Passamaneck et al., 2015), while in N. anomala the orthologous gene is expressed in the whole mesoderm (Fig. 2G6-7). Foxf and foxc expression confines in the anterior mesoderm in both brachiopod species (Passamaneck et al., 2015) (Fig. 2J47 and S3) (Martín-Durán et al., 2016), while in Ph. harmeri foxf is expressed in both the anterior and posterior mesoderm (Fig. 3J4-9) and transcripts of foxc are only detected in the posterior mesoderm (Fig. 3H8-9). Dachs seems to be absent from the anterior mesodermal pattering in Ph. harmeri (Fig. 3F2-9), while in T. transversa it demarcates the entire mesoderm (Passamaneck et al., 2015), and in N. anomala it mainly occupies anterior (apical) mesodermal fates (Fig. 2F6-7). Finally, hox3, was previously described to be expressed in mid/posterior mesodermal domains in brachiopods (Schiemann et al., 2017), but not in Ph. harmeri, where the orthologous gene is solely expressed in the metasomal sac (Gąsiorowski and Hejnol, 2020). These data show that in all three organisms the different subsets of mesoderm development exhibit differences not only in the recruitment of regulatory genes but also in their temporal and spatial expression profiles, suggesting diverse mesodermal patterning mechanisms. 
bioRxiv preprint doi: https://doi.org/10.1101/2020.08.13.249714; this version posted August 13,2020 . The copyright holder for this preprint

(which was not certified by peer review) is the author/funder, who has granted bioRxiv a license to display the preprint in perpetuity. It is made available under aCC-BY-NC 4.0 International license.

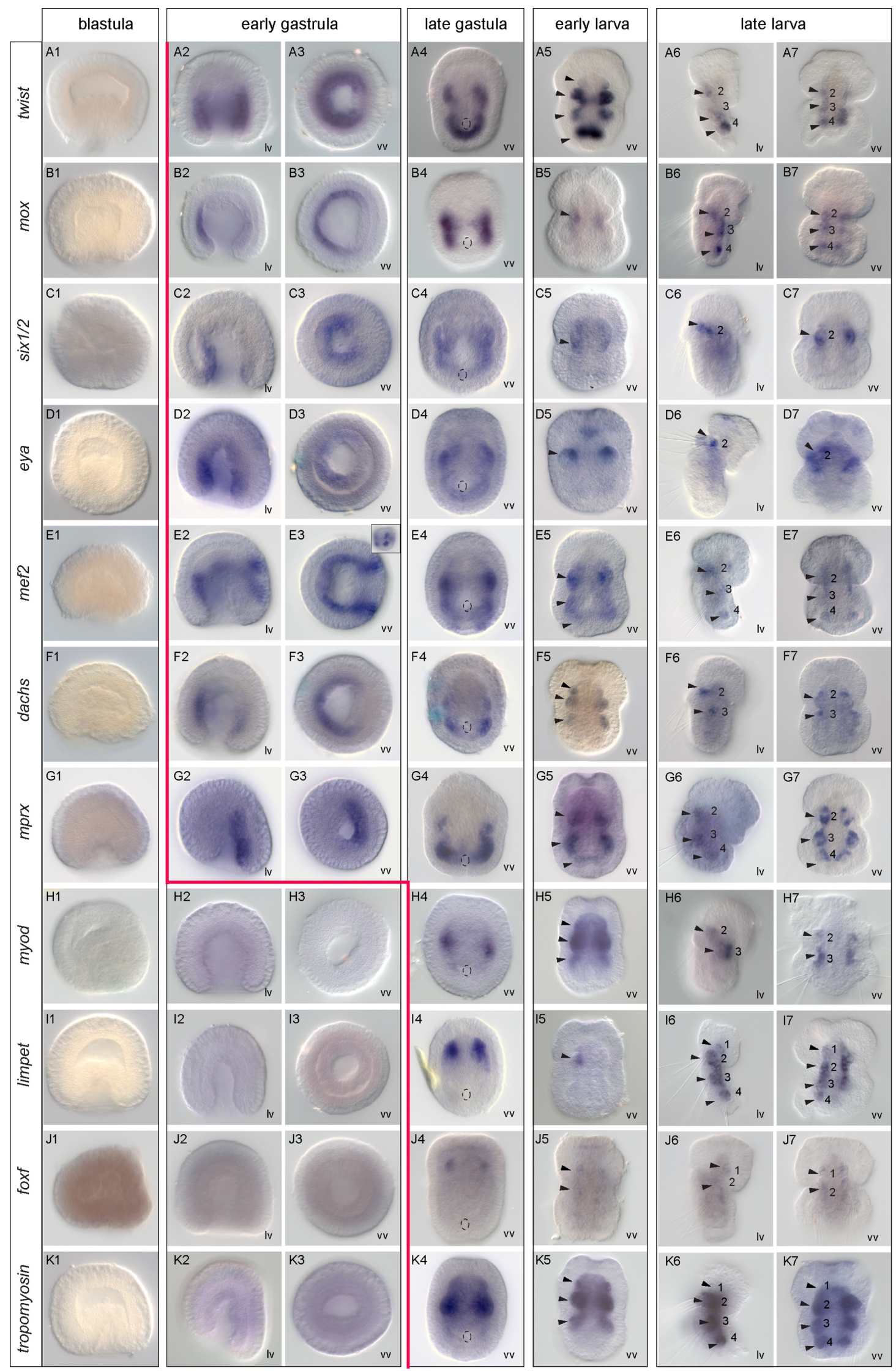

Fig. 2. Mesodermal gene expression during $\mathbf{N}$. anomala development. WMISH of twist, mox, six 1/2, eya, mef2, dachs, mprx, myod, limpet, foxf and tropomyosin in blastulae, early gastrulae, late gastrulae, early larvae and late larvae of $N$. anomala. The inset in panel E3 
shows a different focal plane of the embryo. The position of the blastopore is indicated with a dashed circle in the late gastrula stages. Black arrowheads indicate the coelomic sacs, in which gene expression is detected. The red line marks the onset of mesodermal gene expression. Anterior to the top. Iv, lateral view; vv, vegetal view.

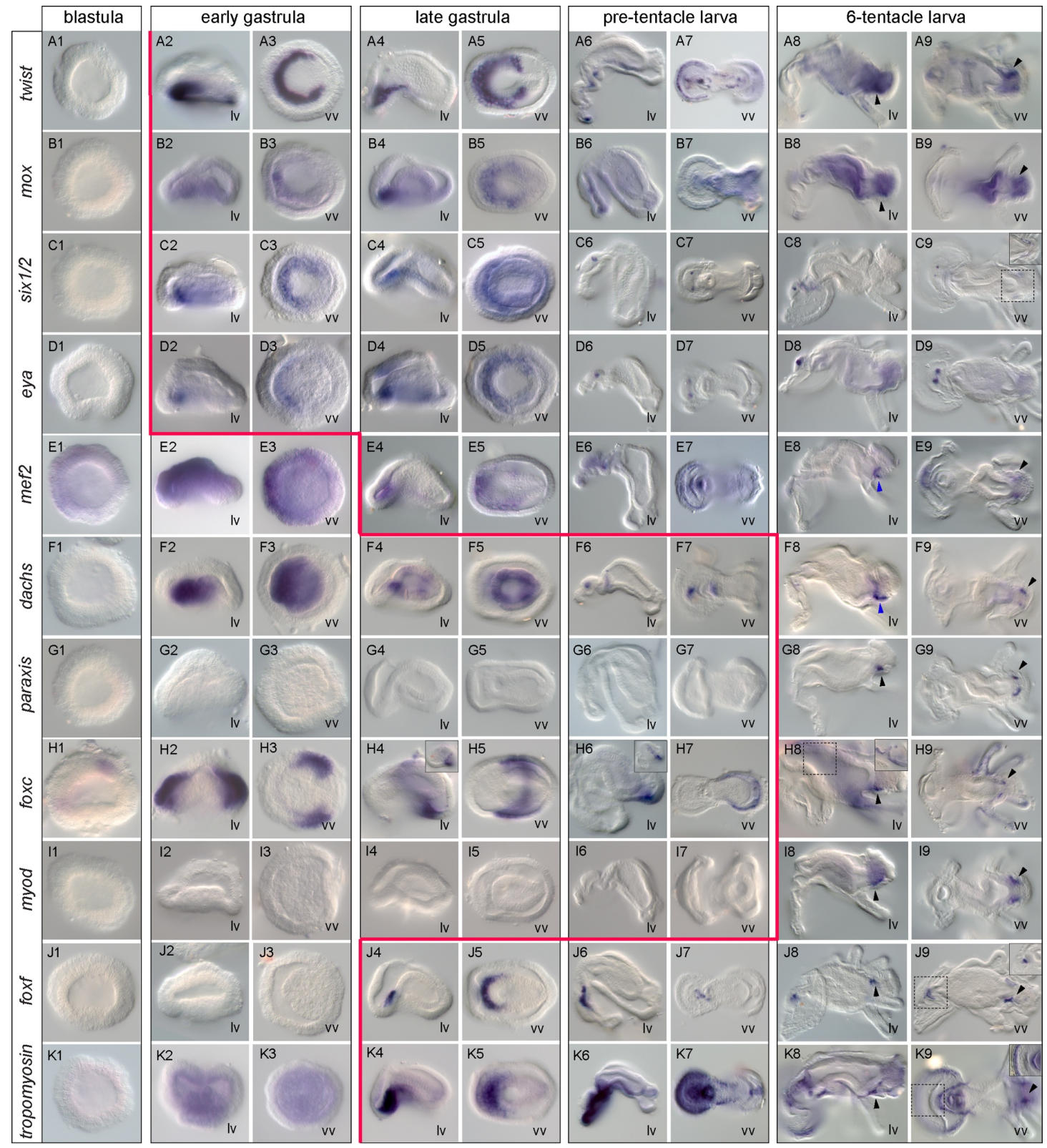

Fig. 3. Mesodermal gene expression during Ph. harmeri development. WMISH of twist, mox, six1/2, eya, mef2, dachs, paraxis, foxc, myod, foxf and tropomyosin in blastulae, early gastrulae, late gastrulae, pre-tentacle larvae and 6-tentacle larvae of Ph. harmeri. Insets in panels $\mathrm{H} 4$ and $\mathrm{H} 6$ show different focal planes of the embryos and insets in panels $\mathrm{C} 9, \mathrm{H} 8, \mathrm{~J} 9$ and $\mathrm{K} 9$ show higher magnifications of the indicated domains. Black arrowheads indicate expression in the posterior mesoderm. Blue arrowheads show expression in the metasomal sac. The red line marks the onset of mesodermal gene expression. Anterior to the left. Iv, lateral view; vv, vegetal view. 


\section{Gene expression of FGF signaling components suggest their possible association with mesoderm and neuronal development}

Three FGF receptors were found in N. anomala and T. transversa but only one in Ph. harmeri (Fig. S1). Moreover, all three animals possess one copy of FGF9/16/20 and FGF8/17/18 ligands (Fig. S1). In T. transversa $f g f r 1$ is expressed in few cells at the vegetal pole at the blastula stage (Fig. 4A1). In gastrulae, transcripts of the gene are demarcating the invaginating endomesoderm (Fig. 4A2) and this expression is retained at the larva stages, in the archenteron, the posterior mesoderm and the developing chaetae sacs (Fig. 4A3). In larvae, $f g f r l$ is additionally activated in anterior scattered cells, resembling neurons (Fig. 4A4). Fgfr 2 is strongly expressed in the animal pole of the blastula in a salt and pepper pattern, suggesting neuronal expression (Fig. 4B1). This expression persists in the gastrula and early larva stages (Fig. 4B2-3) but in late larvae it disappears (Fig. 4B4). The third FGF receptor, fgfr3, is expressed transiently in blastulae, in few cells of the animal pole (Fig. 4C1), while at the gastrula stage it is also expressed faintly is a small cell cluster of the anterior portion of the invaginating endomesoderm (Fig. 4C2). Larvae are cleared from $f g f r 3$ transcripts (Fig. 4C3-4). The two ligands also exhibit a very distinct expression from each another. Fgf9/16/20 is expressed in few cells of the animal pole from the blastula stage up to the larva stage (Fig. 4D1-4). In contrast, $f g f 8 / 17 / 18$ (Vellutini and Hejnol, 2016) starts to be expressed at the blastula stage in an anterior-ventral ectodermal half ring (Fig. 4E1), while in gastrulae, transcripts of the gene are detected in transverse ventral bands reaching the anterior domain of the blastopore, and the future apical organ (Fig. 4E2). In early larvae, $f g f 8 / 17 / 18$ is expressed in two lateral spots, which correspond to the developing chaetae sacs, in anterior cellular patches, as well as in one ventral pair of spots proximal to the mouth and another dorsal pair. Moreover, a new domain of expression at the posterior tip gets activated (Fig. 4E3). Finally, in late larvae, the ventral expression disappears and $f g f 8 / 17 / 18$ is only expressed in the anterior patches, the chaetae sacs and the posterior tip (Fig. 4E4). The analysis of the spatial expression of the three receptors and the two ligands suggests a putative involvement of FGFR1 and FGF8/17/18 in mesoderm development (see co-expression of $f g f r l$ and $f g f 8 / 17 / 18$ in Fig. S4).

In N. anomala none of the FGF signaling components is expressed at the blastula stage, which differs from what is observed in T. transversa (Fig. 4A5, B5, C5). The expression of all $f g f$ receptors is detected at the gastrula stage, in the invaginating archenteron and the developing coelomic sacs (Fig. 4A6, B6, C6). Additionally, transcripts of $f g f r l$ are 
found in the anterior ectoderm (Fig. 4A6). In early larvae, $f g f r l$ is expressed in anterior ectodermal cells, the invaginating mesoderm and the tip of the archenteron (Fig. 4A7). At the late larva stage, $f g f r 1$ expression confines in the two anterior pairs $(\operatorname{cs} 2-\operatorname{cs} 3)$ of chaetae sacs (Fig. 4A8). Fgfr2 and fgfr3 are mainly expressed in the forming archenteron and the invaginating mesoderm at the early larva stage (Fig. 4B7, C7) but $f g f r 2$ is further detected in two anterior-lateral ectodermal patches (Fig. 4B7). Finally, in larvae, $f g f r 2$ is expressed in all four pairs (cs1-cs2-cs3-cs4) of coelomic sacs (Fig. 4B8), while $f g f r 3$ is only expressed in the mouth region (Fig. 4C8). The two ligands also start to be expressed during gastrulation. $F g f 9 / 16 / 20$ expression is initially detected in the anterior ectoderm (Fig. 4D6) but in larvae the ectodermal expression fades and a new mesodermal domain appears in the three coelomic pairs $(\operatorname{cs} 2-\operatorname{cs} 3-\operatorname{cs} 4)$ of chaetae sacs (Fig. 4D7-8). Fgf8/17/18 (Vellutini and Hejnol, 2016) is expressed in two ectodermal bands that encircle the gastrula, one more posterior near the blastopore and another at the mid part of the embryo (Fig. 4E6). In early larvae, transcripts of the gene are detected in the three developing pairs of chaetae sacs $(\operatorname{cs} 2-\operatorname{cs} 3-\operatorname{cs} 4)$ and the ectodermal patches adjacent to the first pair (cs2) (Fig. 4E7) and at the late larva stage the expression of $f g f 8 / 17 / 18$ is restricted to the most posterior pair (cs4) of chaetae sacs (Fig. 4E8). Based on their expression, these data suggest that all three receptors and both ligands are possibly related to mesoderm development in N. anomala.

In Ph. harmeri, the only FGF receptor is already expressed at the blastula stage, in the vegetal pole (Fig. 4F1). At the early gastrula stage, the gene is expressed in an anterior ventro-lateral cell population of the vegetal plate, the presumptive mesoderm, the anterior blastoporal lip, as well as the anterior ectoderm that will give rise to the apical organ (Fig. 4F2-3). In late gastrulae, the gene is expressed in anterior migrating mesodermal cells and a posterior cell cluster located adjacent to the developing intestine (Fig. 4F4-5). At the early larva and pre-tentacle larva stages, the expression of $f g f r$ remains in clusters of cells of the pre-oral mesoderm, two ventro-lateral mesodermal tiers, the posterior cell cluster, the ventral ectoderm and the apical organ (Fig. 4F6-9). $F g f 9 / 16 / 20$ and $f g f 8 / 17 / 18$ exhibit very different expression profiles. $F g f 9 / 16 / 20$ is transiently expressed in the anterior mesoderm and the forming apical organ until the late gastrula stage (Fig. 4G2-5). Fgf8/17/18 exhibits a more dynamic expression, detected in the anterior lip of the blastopore, the anterior-ventral ectoderm and the anterior endoderm in early gastrulae (Fig. 4H2-3), while in later gastrulae and larvae $f g f 8 / 17 / 18$ is expressed in the anterior-ventral ectoderm of the oral hood, a postero- 
ventral group of ectodermal cells and the mouth (Fig. 4H4-9). These data show that also in Ph. harmeri, the expression of FGFR and FGF8/17/18 is possibly associated to mesoderm formation (see coexpression of $f g f r$ and $f g f 8 / 17 / 18$ in Fig. S4). Overall, FGF signaling is likely involved in mesoderm development, as well as neuroectodermal patterning and apical organ formation in all three organisms. A summary of the expression of the FGF signaling components in N. anomala, T. transversa and Ph. harmeri is provided in Fig. S5.
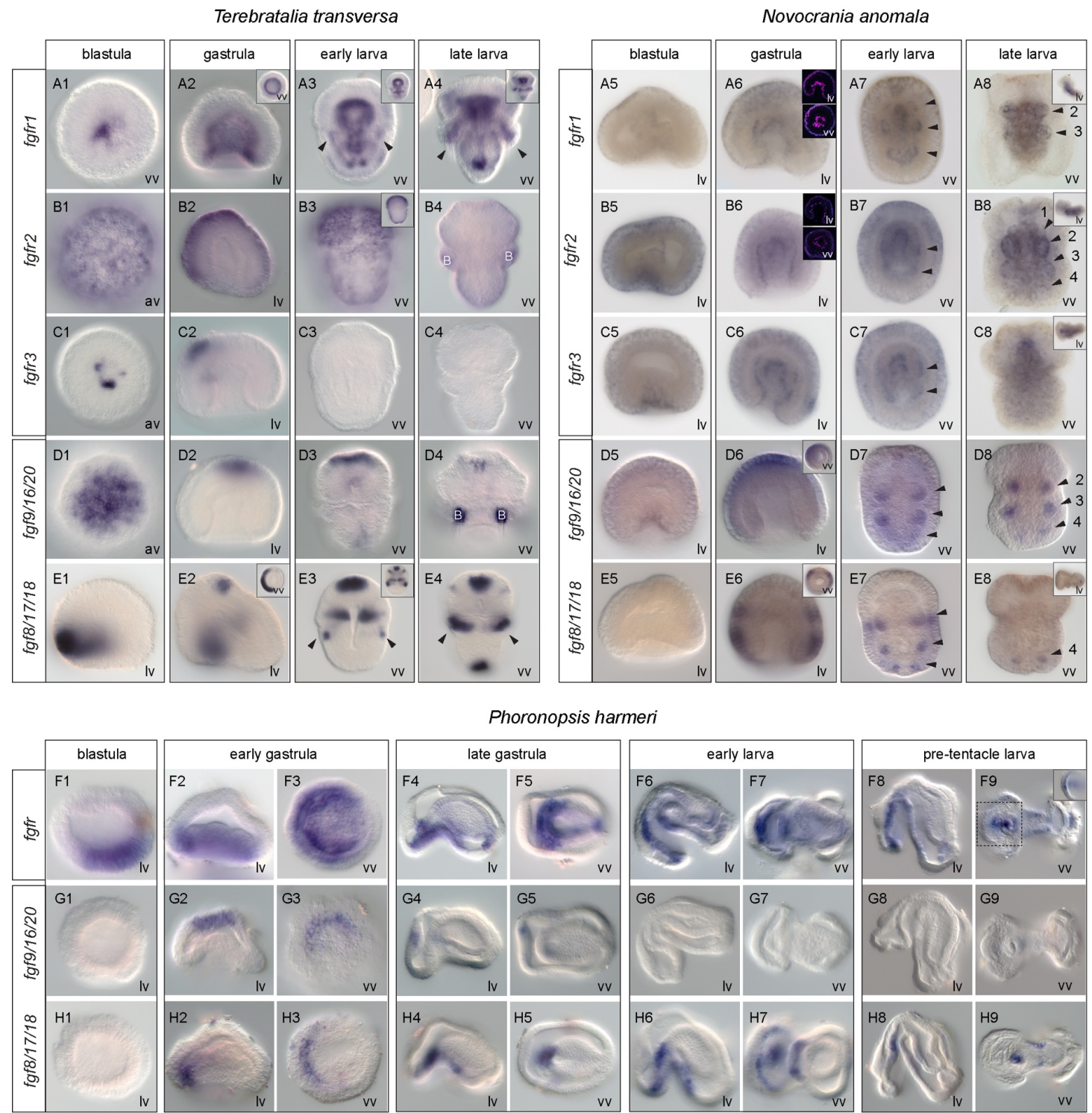

Fig. 4. Gene expression of FGF signaling components in lophophorates. WMISH of fgfr1, fgfr2, fgfr $3, f g f 8 / 11 / 18$ and fgfg/16/20 during the blastula, gastrula, early larva and larva stages of development of $T$. transversa, N. anomala and Ph. harmeri. Insets in panels A3, A4, B3 and E3 show different focal planes of the embryos, insets in panels A2, E2, D6 and E6 show vegetal views, panel B2 shows an animal view and panels A8, B8, C8, D8, E8 shows lateral views. Insets in A6 and B6 show fluorescent WMISH. The inset in panel A9 shows a higher magnification of the indicated domain. Black arrowheads indicate the coelomic sacs, in which 
gene expression is detected. For T. transversa, $N$. anomala anterior to the top and for $P h$. harmeri anterior to the left. av, animal view; Iv, lateral view; vv, vegetal view.

\section{Perturbation of FGF signaling results in failure in mesoderm formation in $N$. anomala but not in $T$. transversa.}

Based on the mesoderm-related expression of some FGF signaling components we hypothesized that FGF might be involved in mesoderm development in brachiopods. To test this, we treated embryos at different developmental stages with SU5402, a selective inhibitor of FGFR (Mohammadi et al., 1997) (for a summary of treatments see Fig. S6). SU5402 treatment abolished the formation of chaetae sacs and neuropile in larvae of both brachiopod species (Fig. 5). However, a difference was observed in mesoderm formation.

T. transversa treated larvae were not compartmentalized in apical, mantle and pedicle lobes, but instead were remaining spherical with an open blastopore, when we treated them from the blastula stage (Fig. 5a). The chaetae bundles were not formed, and the musculature was impaired (Fig. 5a). To ensure that we inhibit FGFR before mesoderm originates, we also treated larvae from the morula stage, which resulted in spherical embryos without a blastopore (Fig. 5a). To understand whether this truncated phenotype was due to a failure of axial elongation or a disruption of the anteriorposterior patterning, we tested the expression of anterior (otx, nk2.1) (Fig. 5aA-A', BB'") and posterior markers (evx) (Martín-Durán et al., 2016) (Fig. 5aC-C'") and found them unaffected. The expression of the endoderm markers $c d x$ and foxa (Martín-Durán et al., 2016) was also unaltered (Fig. 5aD-D", E-E"). We then examined the treated animals for the muscle differentiation marker tropomyosin (Passamaneck et al., 2015) and a loss of posterior expression was observed (Fig. 5aF-F"'). We then tested the expression of the transcription factors twist and foxf, markers of anterior/apical mesoderm (Passamaneck et al., 2015) (Fig. 5aG-G', H-H'), hox3, a marker of mid/mantle mesoderm (Schiemann et al., 2017) (Fig. 5aI-I'), and nkl, a marker of posterior/pedicle mesoderm (Passamaneck et al., 2015) (Fig. 5aJ-J'') and found them unchanged. Interestingly, the expression of foxc, a marker of the most posterior mesoderm (Passamaneck et al., 2015) was lost (Fig. 5aK-K'), suggesting a role of this gene in a later, differentiation step of mesoderm (see also Fig. S7). Moreover, when we treated animals from a later developmental stage (mid gastrula), the phenotype was milder, the posterior mesodermal expression of foxc was recovered and tropomyosin 
expression was extended more posteriorly compared to the larvae treated from the blastula stage (Fig. S8a). These results suggest that in T. transversa, FGF signaling is involved in neuropile formation, coordination of morphogenetic movements of gastrulation and axial elongation. It does not have a role in mesoderm induction (see also Fig. S9), but instead in mesoderm migration and differentiation (as seen from the loss of chaetae sacs). Since in T. transversa the direction of axial elongation is taking place from anterior-dorsal to posterior (Freeman, 1993; Martín-Durán et al., 2016), the inhibition in posterior axial elongation is probably coupled with the failure in mesoderm migration and differentiation.

$N$. anomala treated animals did not exhibit the same phenotype that we observed in $T$. transversa (Fig. 5b). Larvae treated from the blastula stage were smaller than the controls, but they were not spherical, and they possessed an elongated archenteron without a mouth opening (Fig. 5b). Also, mesoderm was impaired; only one out of the four pairs of coelomic sacs was present and none of the chaetae bundles were formed (Fig. 5b). When we looked at the anterior-posterior patterning genes (Martín-Durán et al., 2016) we observed an apical reduction and a complete loss of expression in the mouth region of the genes otx and $n k 2.1$ (Fig. 5bL-L', M-M'). The most posterior fate was also impaired, as shown from the reduced expression of evx (Fig. 5bN-N'). The expression of the endodermal markers $c d x$ and foxa (Martín-Durán et al., 2016), however, remained unaffected (Fig. 5bO-O', P-P'). We then tested the expression of limpet, a pan-mesodermal differentiation marker in this species. We saw a severe reduction of expression and detection in only one anterior coelomic sac (Fig. 5bQ-Q'). The expression of the anterior mesodermal marker foxf (Martín-Durán et al., 2016) was not affected (Fig. 5bR-R'), but instead transcripts of foxc (Martín-Durán et al., 2016), which in control larvae confine in the most anterior coelomic sac (cs1), were lost (Fig. $\left.5 \mathrm{bS}-\mathrm{S}^{\prime}\right)$, suggesting that the formation of cs1 was abolished. Finally, the expression of the posterior mesodermal markers twist (Martín-Durán et al., 2016) and hox3 (Schiemann et al., 2017) were inhibited (Fig. 5bT-T', U-U'). Similar results were obtained when the embryos were treated from the gastrula stage, with the exception of hox3, the expression of which was partly recovered (Fig. S8b), indicating that the input of FGF on hox 3 occurs sometime between the blastula and gastrula stage. In order to understand which step of mesoderm development had been compromised, we also tested the expression of the mesodermal marker twist in gastrulae treated from the blastula stage on, and found it downregulated, suggesting that mesoderm induction was 
compromised (Fig. S9). These data suggest that in N. anomala, FGF is involved in anteroposterior patterning, neuropile formation, mouth formation, as well as the most anterior and posterior mesoderm formation and mesoderm differentiation (as seen from the loss of chaetae sacs). However, an impact in axial elongation is not evident, as shown in T. transversa, further supported by the fact that in $N$. anomala the direction of axial elongation is occurring from posterior-ventral to anterior (Freeman, 2000; Martín-Durán et al., 2016; Nielsen, 1991). 

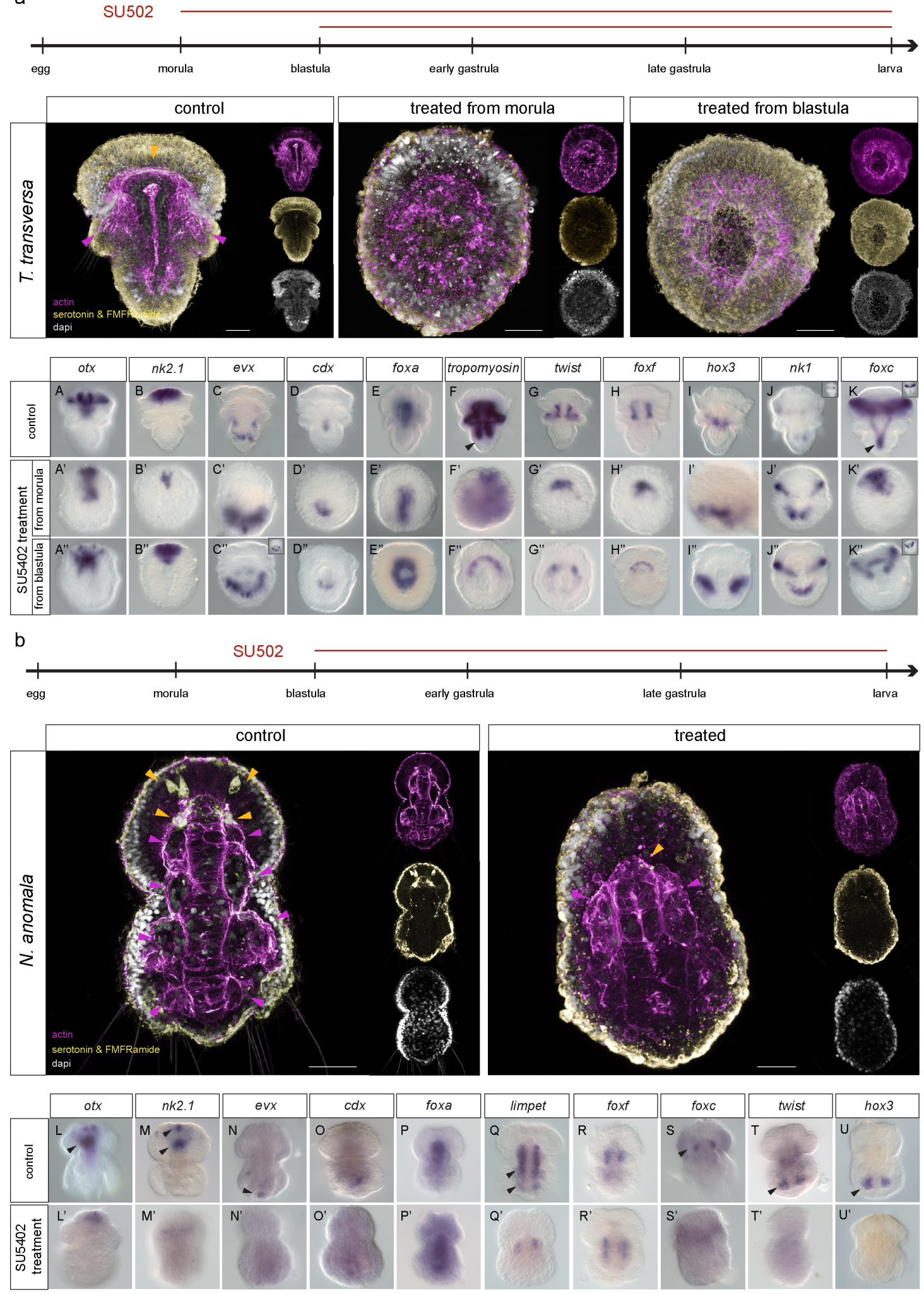

Fig. 5. SU5402 treatments in brachiopods. (a) Immunohistochemistry of markers of the nervous system (serotonin, FMFRamide) and musculature (actin) in T. transversa morula and blastula embryos treated with 20 uM SU5402 and fixed at larva stage. WMISH of anterior (otx, $n k 2.1$ ), posterior (evx) and endodermal (foxa, $c d x$ ) genes, musculature (tropomyosin), anterior mesoderm (twist, foxf), mid mesoderm (hox3) and posterior mesoderm (nk1, foxc) in $T$. transversa morula and blastula embryos treated with 20 uM SU5402 and fixed at larva stage. Insets in panels $\mathrm{J}, \mathrm{K}, \mathrm{C}$ " and $\mathrm{K}$ " show different focal planes of the embryos. (b) 
Immunohistochemistry of markers of the nervous system (serotonin, FMFRamide) and musculature (actin) in N. anomala blastula embryos treated with 20 uM SU5402 and fixed at larva stage. WMISH of anterior (otx, nk2.1), posterior genes (evx) and endodermal (foxa, $c d x$ ) genes, the whole mesoderm (limpet), anterior mesoderm (foxf, foxc) and posterior mesoderm (twist, hox3), in N. anomala blastula embryos treated with 20 uM SU5402 and fixed at larva stage. Black arrowheads indicate the domains of expression that are absent in the treated embryos. Yellow arrowheads indicate the neuropile and magenta arrowheads the musculature associated to coelomic and chaetae sacs. All panels depict embryos in vegetal view. Every fluorescent image is a full projection of merged confocal stacks and nuclei are stained with DAPI. Anterior to the top. Drawings are not up to scale. Scale bar: 20 um.

\section{FGF signaling is upstream of mesoderm induction in Ph. harmeri.}

To test whether the role of FGF signaling in mesoderm induction extends beyond the brachiopod lineage, we also treated embryos of Ph. harmeri with SU5402 at different developmental stages (for a summary of treatments see Fig. S6). SU5402 treatment from the blastula stage inhibited the formation of musculature and the apical organ of pre-tentacle larvae (Fig. 6a). The treated larvae exhibited a truncated phenotype with a shorter archenteron that didn't have a visible opening (Fig. 6a). The expression of the mesodermal markers twist, six3/6 (Andrikou et al., 2019) and foxf was abolished (Fig. $\left.6 \mathrm{aA}-\mathrm{F}^{\prime}\right)$, and the same was observed for the markers of the apical organ six3/6 and otx (Andrikou et al., 2019) (Fig. 6aC-D', I-J'). The ectodermal expression of foxc, was only dorsally affected (Fig. 6aK-L'). Finally, the posterior endodermal expression of $n k 2.1$ (Fig. 6aG-H') and the expression of foxa (Andrikou et al., 2019) in the mouth (Fig. 6aM-N') were downregulated. A treatment from the gastrula stage on, resulted in a milder phenotype (Fig. S10). Some mesodermal cells were present, the apical organ was recovered, and the mouth was formed (Fig. S10). Moreover, the posterior endodermal expression of $n k 2.1$-as well as foxa expression in the mouth- was unaffected (Fig. S10). To test whether this was due to a failure in mesoderm induction, we also tested the expression of the mesodermal markers twist and six3/6 in gastrulae treated from the blastula stage on, and found it abolished (Fig. S9). These results show that FGF signaling is upstream of anteroposterior patterning, apical organ formation, gastrulation movements and mesoderm formation in Ph. harmeri. Moreover, an additional participation of FGF in mesoderm migration is also possible due to the coexpression of the mesodermal marker twist and $f g f r$ throughout the development (Fig. $6 b)$.

Overall, our data suggest an evident role of FGF signaling in mesoderm development in the lineage of lophophorates. Moreover, a conserved involvement of FGF in 
anteroposterior patterning, neuron formation, morphogenetic movements of gastrulation and axial elongation is witnessed.

a
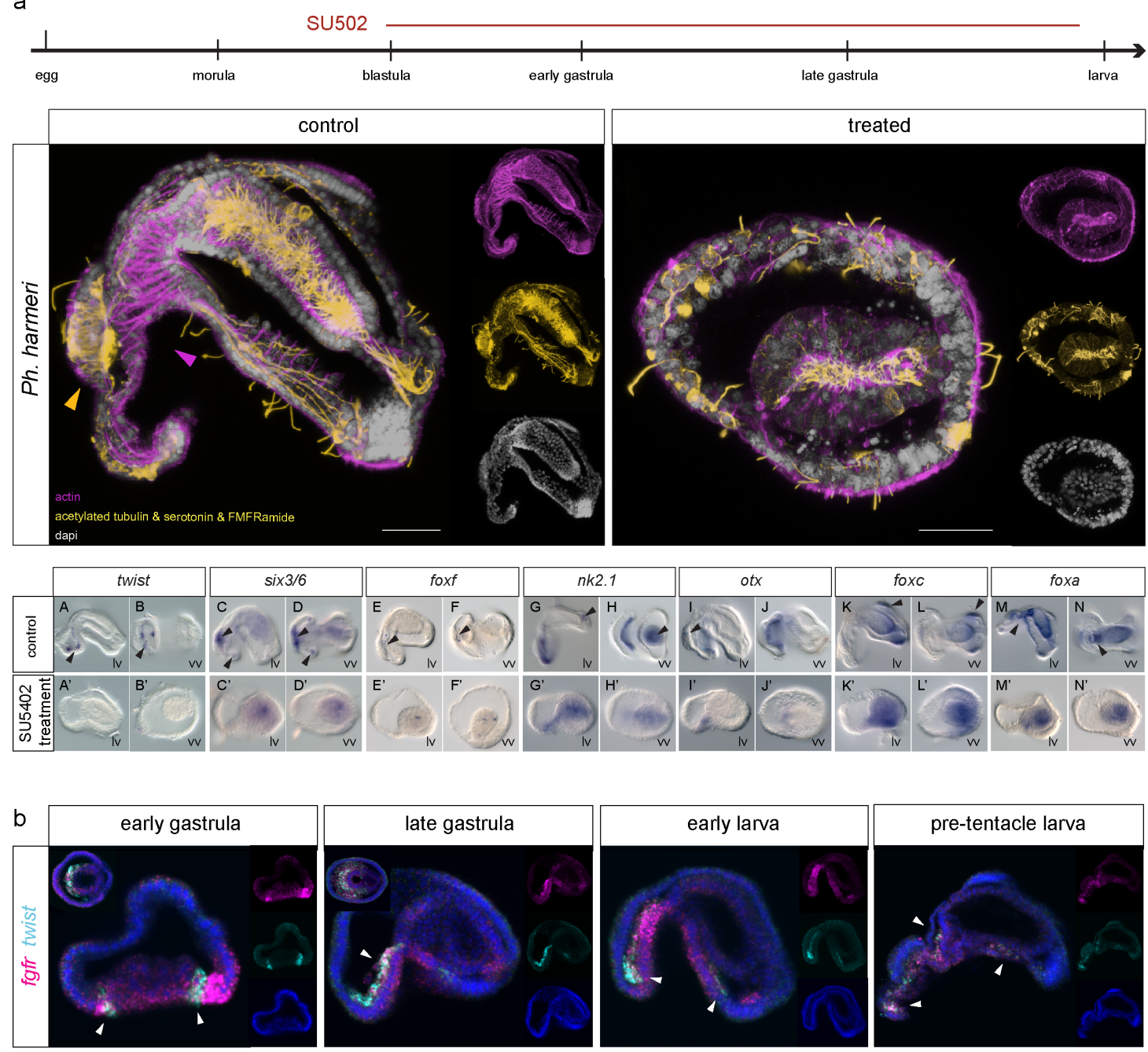

Fig. 6. SU5402 treatments in Ph. harmeri. (A) Immunohistochemistry of markers of the nervous system (acetylated tubulin, serotonin, FMFRamide) and musculature (actin) in Ph. harmeri blastula embryos treated with 20 uM SU5402 and fixed at larva stage. Yellow arrowheads indicate the apical organ and magenta arrowheads the esophageal musculature. WMISH of mesodermal (twist, six3/6, foxf), anterior (six3/6, otx, nk2.1), postero-ventral (foxc) and endodermal (foxa, nk2.1) genes in Ph. harmeri blastula embryos treated with $20 \mathrm{uM}$ SU5402 and fixed at larva stage. Black arrowheads indicate the domains of expression that are absent in the treated embryos. (B) Co-expression analysis of fgfr (magenta) and twist (cyan) by double fluorescent WMISH in gastrula and larva stages of development of $P$ h. harmeri. Right insets show embryos in vegetal view. White arrowheads indicate co-expression. Every fluorescent image is a full projection of merged confocal stacks and nuclei are stained with DAPI. Anterior to the left. Iv, lateral view; vv, vegetal view. Scale bar: 20 um.

\section{Discussion}

\section{Expression dynamics of the mesodermal gene battery}


Nearly all the genes we studied are expressed during mesodermal development in the investigated lophophorate species however, the temporal expression dynamics and spatial recruitment of some genes differ (Fig. S3). While twist, six 1/2 and foxf are expressed in a similar sequential manner in all three organisms, the remaining genes occupy different temporal regulatory positions. The spatial utilization of the genetic repertoire in the differentiated subsets of mesoderm exhibits only few cases of shared spatial similarity in all three species (e.g. mef2, which demarcates the entire mesoderm, and eya, which is mostly expressed in the anterior mesoderm), but the other genes show differences in their spatial transcript distribution. Overall, these results suggest that mesoderm development in lophophorates utilizes a similar set of transcription factors, but their hierarchical deployment differs, suggesting profound differences in their mesodermal patterning and mesoderm regionalization. Data from bryozoans, the potential sister group of phoronids, suggest similar spatial differences in the mesodermal patterning, such as the posterior expression of foxc (Vellutini et al., 2017). Moreover, comparative studies of the expression profiles of endomesoderm and ectomesoderm in lophotrochozoans have revealed some intriguing differences, such as the confinement of twist expression in the ectomesoderm of the mollusks Crepidula fornicata (Perry et al., 2015), Patella vulgata (Nederbragt et al., 2002) and the annelid Capitella teleta (Dill et al., 2007) but not in the annelids A. virens and P. dumerilii, where twist is expressed in both sources of mesoderm (Kozin et al., 2016; Pfeifer et al., 2014; Steinmetz, 2006).

It thus becomes evident that the spatial and temporal differences in lophophorate mesoderm development are observed in more spiralian taxa, which indicates a diversification of mesodermal developmental programs and their underlying GRNs. Different circuitries of GRNs orchestrating the formation of homologous mesodermal derivatives have been described in some animals and support the idea that the evolution of GRNs is mainly based on the developmental regulatory demands of each network (Andrikou and Arnone, 2015; Erkenbrack, 2016; Erkenbrack et al., 2018; Hinman and Davidson, 2007). Therefore, alterations in GRN circuitries do not necessarily reflect convergent evolution of the resulting tissues (Davidson and Erwin, 2006; Peter, 2020), but can also be a product of developmental system drift (True and Haag, 2001).

\section{FGF signaling upstream of different mesodermal populations}


FGF signaling is required for the formation of all or most mesoderm e.g. in hemichordates (Fan et al., 2018; Green et al., 2013) and tunicates (Davidson et al., 2006; Imai et al., 2002; Kim and Nishida, 2001; Yasuo and Hudson, 2007), or a subset of mesoderm e.g. in vertebrates (Amaya et al., 1993; Draper et al., 2003; Fletcher et al., 2006; Fletcher and Harland, 2008; Yamaguchi et al., 1994), cephalochordates (Bertrand et al., 2011), sea urchins (Andrikou et al., 2015) and nematodes (Photos et al., 2006) (S11). According to our results, this is similar to lophophorates, where FGF acts on different levels of mesoderm development. While $N$. anomala utilizes FGF to form two subsets of mesoderm, in Ph. harmeri FGF is upstream of the formation of all mesoderm. It remains unclear why mesodermal subpopulations differ in their promoting requirements and deploy different signals. The acquisition of different signaling pathways, with distinct spatiotemporal expression dynamics and inductive properties, can act as a relay mechanism of the initial signal but can also exhibit diverse functions. An example is the recruitment of Nodal in vertebrate development, which although it interacts synergistically with FGF in promoting mesoderm, it also acts differentially in the induction of mesodermal populations (Kimelman, 2006; Mathieu et al., 2004).

\section{Implications of mesoderm development in gastrulation and axial elongation}

Besides having a role in mesoderm development, FGF signaling has conserved functions in neural development and morphogenetic movements of gastrulation in an array of investigated organisms (Fig. S11). In deuterostomes, FGF is involved both in gastrulation (Amaya et al., 1991; Bertrand et al., 2011; Röttinger et al., 2008) and neural induction (Bertrand et al., 2003; De Robertis and Kuroda, 2004; Garner et al., 2016). Also, in the two well-studied ecdysozoans D. melanogaster and C. elegans, FGF signaling is upstream of axon guidance (Bülow et al., 2004; García-Alonso et al., 2000), and cell migration during gastrulation (in D. melanogaster) (Leptin and Affolter, 2004). In the remaining protostomes data are limited to gastropods and Platyhelminthes, where FGF signaling is involved in neural development (Cebrià et al., 2002; Pollak et al., 2014). Most likely, the involvement of FGF in these developmental processes was already present before the cnidarian-bilaterian split, as witnessed in sea anemones, where FGF seem to act upon gastrulation (Matus et al., 2007), neural development (Matus et al., 2007) and is upstream of apical organ formation (Rentzsch et al., 2008). Our study revealed similar roles of FGF signaling in the investigated lophophorate species. In particular, all three species exhibited defects in their apical organ/neuropile 
formation, as well as loss of a number of differentiated neurons (e.g. serotonergic neurons in Fig. 5b). Moreover, they all showed impaired gastrulation to some degree. Impaired gastrulation can occur either as a direct or indirect effect mediated by a failure in mesoderm formation. For example, in T. transversa, where mesoderm is formed independently of FGF signaling, most likely the role of FGF is only morphogenetic, in orchestrating cell movements during gastrulation. However, in the other two species, where FGF is involved in mesoderm formation, it is still unclear whether the observed failure in gastrulation movements after FGF inhibition is direct, or indirect caused by the lack of mesoderm formation.

Another outcome of this study concerns the evident relationship witnessed between mesoderm development and posterior axis elongation in T. transversa. The expression of $f g f 8 / 11 / 18$ mRNA in the growing posterior tip of the embryo in relation to $f g f r l$ (Fig. S4), suggests that FGF8/11/18 might act as a gradient that progressively coordinates the posterior elongation of the embryo and mesoderm differentiation, similar to what has been described in vertebrates (Dubrulle and Pourquie, 2004). The role of FGF signaling in the posterior axial elongation of $T$. transversa resembles mechanisms typically deployed by a number of deuterostomes in order to coordinate embryonic patterning and elongation of posterior tissues: in the tunicate species Ciona intestinalis, FGF, together with the canonical WNT and Retinoic Acid (RA) signaling, are establishing the posterior patterning of the tail (Pasini et al., 2012), in amphioxus FGF and RA are coordinating the posterior elongation (Bertrand et al., 2015), and in vertebrates the AP axial elongation of the trunk is mediated by an antagonistic interplay of FGF and RA, where high RA or low FGF results in cessation of posterior embryonic regions (Deng et al., 1994; Partanen et al., 1998; Yamaguchi et al., 1994). Data from RA signaling are currently unavailable in lophophorates; however, WNT signaling also appears to be involved in axis patterning and the establishment of posterior identities (Martín-Durán et al., 2016; Vellutini and Hejnol, 2016), which suggest a conserved coordinated function of WNT and FGF signaling in regulating posterior axial elongation.

To summarize, the data provide support for a conserved involvement of FGF signaling in gastrulation movements and axial elongation, with the phenotypic severity to vary, depending on the developmental mode of mesoderm formation of the investigated species. A coordinated interplay of WNT and FGF signaling in regulating posterior 
axial elongation seems also likely, suggesting a putative conserved developmental signaling mechanism in orchestrating posterior regionalization.

\section{The recurrent use of FGF signaling in mesoderm formation}

The role of FGF signaling in mesoderm induction was thought to be restricted to deuterostomes. After investigating three species of lophophorates, we are able to show that the mesoderm-inducing ability of this pathway extends beyond the lineage of deuterostomes. However, signaling pathways are often deployed as upstream "plug-in" devices and can be co-opted and exchanged to serve different developmental processes within and among species (Davidson and Erwin, 2006). To determine whether the involvement of FGF signaling in mesoderm formation was already present in the last common ancestor of Bilateria, or whether it was independently co-opted in the lineage of lophophorates, functional studies from more spiralian taxa are required. So far, the only available data in favour of a putative conserved role of FGF in mesoderm induction come from studies in mollusks, where MAPK, one of the major downstream targets of FGF signaling (Ornitz and Itoh, 2015), is upstream of endomesoderm specification (Koop et al., 2007; Kozin et al., 2013; Lambert, 2008; Lambert and Nagy, 2001; Lambert and Nagy, 2003). Moreover, a putative conserved FGF signaling event on mesoderm induction is possibly also present in bryozoans, as suggested from the activation of the MAPK pathway in the mesodermal precursor 3D (Vellutini et al., 2017), which would imply that the inductive role of FGF signaling in mesoderm was present at least in the last common ancestor of lophophorates.

\section{Materials and methods}

\section{Animal systems}

Gravid adult specimens were collected in Bodega bay, California, USA (Phoronopsis harmeri Pixell, 1912), in Friday Harbor Laboratories, U.S.A. (Terebratalia transversa Sowerby, 1846), in Espeland Marine Biological Station, Norway (Novocrania anomala Müller, 1776) and spawned as previously described (Freeman, 1993; Freeman, 2000; Rattenbury, 1954). The embryos were kept in clean seawater and collected at various stages of development. 


\section{Gene cloning and orthology assignment}

Putative orthologous sequences of genes of interest were identified by tBLASTx search against the transcriptomes of Terebratalia transversa, Novocrania anomala and Phoronopsis harmeri. Gene orthology of genes of interest identified by tBLASTx was tested by reciprocal BLAST against NCBI Genbank and followed by phylogenetic analyses. Amino acid alignments were made with MUSCLE. IQ-tree (version 2.0.5) was used to conduct a maximum likelihood phylogenetic analysis. Fragments of the genes of interest were amplified from cDNA of T. transversa, N. anomala and Ph. harmeri by PCR using gene specific primers. PCR products were purified and cloned into a pGEM-T Easy vector (Promega, USA) according to the manufacturer' $s$ instruction and the identity of inserts confirmed by sequencing.

\section{SU5402 treatments}

SU5402 was dissolved in DMSO to a final concentration of $5 \mathrm{um}, 10 \mathrm{uM}$ and $20 \mu \mathrm{M}$. Higher concentrations than these were lethal to the embryos. SU5402 was added at morula, blastula and gastrula stages up to the fixation stage. A corresponding volume of DMSO was added in the control embryos. Solutions were changed every $24 \mathrm{~h}$. A table summarizing the drug treatments and observed phenotypes is seen in Fig. S6.

\section{Whole Mount In Situ Hybridization}

Embryos were manually collected, fixed in 4\% paraformaldehyde in SW for 60 minutes, permeabilised in 100\% Methanol overnight and processed for in situ hybridization as described in (Andrikou et al., 2019; Martín-Durán et al., 2016; Santagata et al., 2012). Labeled antisense RNA probes were transcribed from linearized DNA using digoxigenin-11-UTP (Roche, USA) according to the manufacturer's instructions.

\section{Whole Mount Immunohistochemistry}

Embryos were permeabilised in 100\% Methanol for 1 hour, digested with Proteinase $\mathrm{K}\left(10 \mu \mathrm{g} \mathrm{ml}^{-1}\right)$ for 5 minutes, fixed in $4 \%$ paraformaldehyde in SW for 30 minutes, washed for 3 hours in 1\% PTX, washed in PBT and incubated in 4\% sheep serum in PBT for $30 \mathrm{~min}$. The animals were then incubated with commercially available primary antibodies (anti-acetylated tubulin mouse monoclonal antibody (Sigma-Aldrich); antiactin mouse monoclonal antibody (Seven Hills Bioreagents); anti-serotonin, rabbit 
monoclonal antibody (Sigma-Aldrich); anti-FMFRamide rabbit monoclonal antibody (Immnunostar); anti-HB9 rabbit monoclonal antibody (Invitrogen) overnight at $4{ }^{\circ} \mathrm{C}$, washed 3 times in PBT, and followed by incubation in 4\% sheep serum in PBT for 30 min. Specimens were then incubated with secondary anti-rabbit and anti-mouse antibodies Alexa Fluor overnight at $4^{\circ} \mathrm{C}$ followed by 3 washes in PTW. Nuclei were stained with DAPI (Molecular probes) and F-actin was visualized with BODIPY FL Phallacidin (Molecular probes).

\section{Documentation}

Colorimetric WMISH specimens were imaged with a Zeiss AxioCam HRc mounted on a Zeiss Axioscope A1 equipped with Nomarski optics and processed through Photoshop CS6 (Adobe). Fluorescent-labeled specimens were analyzed with a SP5 confocal laser microscope (Leica, Germany) and processed by the ImageJ software version 2.0.0-rc-42/1.50d (Wayne Rasband, NIH). Fig. plates were arranged with Illustrator CS6 (Adobe).

\section{Acknowledgements}

We thank all members from Hejnol's group for contributing with animal collection and spawning. We are grateful to Chris Lowe for hosting us in his lab for Phoronopsis harmeri collection and spawning. We also thank Paul Bump from Lowe lab and Karl Menard from Bodega Bay Marine Lab for their help with collecting Phoronopsis harmeri adults. We are grateful to the "Centennial" boat crew of Friday Harbor and the Espeland marine biological station personnel for the T. transversa and $N$. anomala collections, respectively.

\section{Competing interests}

The authors declare that they have no competing interests.

\section{Funding}

This research was funded by the Sars Centre core budget and the European Research 
Council Community's Framework Program Horizon 2020 (2014-2020) ERC grant agreement 648861 to $\mathrm{AH}$.

\section{Authors' contributions}

CA designed the study, performed the collections and conducted the experiments. CA and $\mathrm{AH}$ performed the collections, analyzed the data and wrote the manuscript.

\section{Data availability}

All newly determined sequences have been deposited in GenBank under the accession numbers xxxxx. Primer sequences are available on request.

\section{References}

Altenburger, A. and Wanninger, A. (2010). Neuromuscular development in Novocrania anomala: evidence for the presence of serotonin and a spiralian-like apical organ in lecithotrophic brachiopod larvae. Evol. Dev. 12, 16-24.

Amaya, E., Musci, T. J. and Kirschner, M. W. (1991). Expression of a dominant negative mutant of the FGF receptor disrupts mesoderm formation in Xenopus embryos. Cell 66, 257-270.

Amaya, E., Stein, P. A., Musci, T. J. and Kirschner, M. W. (1993). FGF signalling in the early specification of mesoderm in Xenopus. Development 118, 477487.

Amin, N. M., Lim, S. E., Shi, H., Chan, T. L. and Liu, J. (2009). A conserved Six-Eya cassette acts downstream of Wnt signaling to direct non-myogenic versus myogenic fates in the C. elegans postembryonic mesoderm. Dev. Biol. 331, 350-360.

Amin, N. M., Shi, H. and Liu, J. (2010). The FoxF/FoxC factor LET-381 directly regulates both cell fate specification and cell differentiation in $C$. elegans mesoderm development. Development 137, 1451-1460.

Andrikou, C. and Arnone, M. I. (2015). Too many ways to make a muscle: evolution of GRNs governing myogenesis. Zool. Anz. 256, 2-13.

Andrikou, C., Iovene, E., Rizzo, F., Oliveri, P. and Arnone, M. I. (2013). Myogenesis in the sea urchin embryo: the molecular fingerprint of the myoblast precursors. EvoDevo 4, 33.

Andrikou, C., Pai, C. Y., Su, Y. H. and Arnone, M. I. (2015). Logics and properties of a genetic regulatory program that drives embryonic muscle development in an echinoderm. eLife 4.

Andrikou, C., Passamaneck, Y. J., Lowe, C. J., Martindale, M. Q. and Hejnol, A. (2019). Molecular patterning during the development of Phoronopsis 
harmeri reveals similarities to rhynchonelliform brachiopods. EvoDevo 10, 33.

Beiman, M., Shilo, B. Z. and Volk, T. (1996). Heartless, a Drosophila FGF receptor homolog, is essential for cell migration and establishment of several mesodermal lineages. Genes Dev. 10, 2993-3002.

Bertrand, S., Aldea, D., Oulion, S., Subirana, L., De Lera, A. R., Somorjai, I. and Escriva, H. (2015). Evolution of the role of RA and FGF signals in the control of somitogenesis in chordates. PLoS One $\mathbf{1 0 .}$

Bertrand, S., Camasses, A., Somorjai, I., Belgacem, M. R., Chabrol, O., Escande, M. L., Pontarotti, P. and Escriva, H. (2011). Amphioxus FGF signaling predicts the acquisition of vertebrate morphological traits. Proc. Natl. Acad. Sci. U S A 108, 9160-9165.

Bertrand, V., Hudson, C., Caillol, D., Popovici, C. and Lemaire, P. (2003). Neural tissue in ascidian embryos is induced by FGF9/16/20, acting via a combination of maternal GATA and Ets transcription factors. Cell 115, 615627.

Bülow, H. E., Boulin, T. and Hobert, O. (2004). Differential functions of the $C$. elegans FGF receptor in axon outgrowth and maintenance of axon position. Neuron 42, 367-374.

Burdine, R. D., Branda, C. S. and Stern, M. J. (1998). EGL-17(FGF) expression coordinates the attraction of the migrating sex myoblasts with vulval induction in C. elegans. Development 125, 1083-1093.

Burton, P. M. (2008). Insights from diploblasts; the evolution of mesoderm and muscle. J. Exp. Zoo.l B. Mol. Dev. Evol. 310, 5-14.

Cebrià, F., Kobayashi, S., Umesono, Y., Nakazawa, M., Mineta, K., Ikeo, K., Gojobori, T., Itoh, M., Taira, M., Sánchez Alvarado, A., et al. (2002). noudarake, a novel gene related to FGF receptors is involved in restricting brain tissues to the head region of planarians. Nature.

Chiodin, M., Børve, A., Berezikov, E., Ladurner, P., Martinez, P. and Hejnol, A. (2013). Mesodermal gene expression in the acoel Isodiametra pulchra indicates a low number of mesodermal cell types and the endomesodermal origin of the gonads. PLoS One 8, e55499.

Conklin, E. G. (1902). The embryology of a brachiopod, Terebratulina septentrionalis Couthouy. Proc. Am. Philos. Soc. 41, 41-76.

Davidson, B., Shi, W., Beh, J., Christiaen, L. and Levine, M. (2006). FGF signaling delineates the cardiac progenitor field in the simple chordate, Ciona intestinalis. Genes Dev. 20, 2728-2738.

Davidson, E. H. and Erwin, D. H. (2006). Gene regulatory networks and the evolution of animal body plans. Science 311, 796-800.

De Robertis, E. M. and Kuroda, H. (2004). Dorsal-ventral patterning and neural induction in Xenopus embryos. Annu. Rev. Cell Dev. Biol. 20, 285-308.

Deng, C.-X., Wynshaw-Boris, A., Shen, M. M., Daugherty, C., Ornitz, D. M. and Leder, P. (1994). Murine FGFR-1 is required for early postimplantation growth and axial organization. Genes Dev. 8, 3045-3057.

DeVore, D. L., Horvitz, H. R. and Stern, M. J. (1995). An FGF receptor signaling pathway is required for the normal cell migrations of the sex myoblasts in C. elegans hermaphrodites. Cell 83, 611-620. 
Dill, K. K., Thamm, K. and Seaver, E. C. (2007). Characterization of twist and snail gene expression during mesoderm and nervous system development in the polychaete annelid Capitella sp. I. Dev. Genes Evol. 217, 435-447.

Draper, B. W., Stock, D. W. and Kimmel, C. B. (2003). Zebrafish fgf24 functions with fgf8 to promote posterior mesodermal development. Development 130, 4639-4654.

Dubrulle, J. and Pourquie, 0. (2004). fgf8 mRNA decay establishes a gradient that couples axial elongation to patterning in the vertebrate embryo. Nature 427, 419-422.

Eriksson, B. J. and Tait, N. N. (2012). Early development in the velvet worm Euperipatoides kanangrensis Reid 1996 (Onychophora: Peripatopsidae). Arthropod Struct. Dev. 41, 483-493.

Erkenbrack, E. M. (2016). Divergence of ectodermal and mesodermal gene regulatory network linkages in early development of sea urchins. Proc. Natl. Acad. Sci. U S A 113, E7202-E7211.

Erkenbrack, E. M., Davidson, E. H. and Peter, I. S. (2018). Conserved regulatory state expression controlled by divergent developmental gene regulatory networks in echinoids. Development 145.

Fan, T. P., Ting, H. C., Yu, J. K. and Su, Y. H. (2018). Reiterative use of FGF signaling in mesoderm development during embryogenesis and metamorphosis in the hemichordate Ptychodera flava. BMC Evol. Biol. 18, 120.

Fletcher, R. B., Baker, J. C. and Harland, R. M. (2006). FGF8 spliceforms mediate early mesoderm and posterior neural tissue formation in Xenopus. Development 133, 1703-1714.

Fletcher, R. B. and Harland, R. M. (2008). The role of FGF signaling in the establishment and maintenance of mesodermal gene expression in Xenopus. Dev. Dyn. 237, 1243-1254.

Freeman, G. (1993). Regional specification during embryogenesis in the articulate brachiopod Terebratalia. Dev. Biol. 160, 196-213.

--- (2000). Regional specification during embryogenesis in the craniiform brachiopod Crania anomala. Dev. Biol. 227, 219-238.

--- (2003). Regional specification during embryogenesis in Rhynchonelliform brachiopods. Dev. Biol. 261, 268-287.

Fritzenwanker, J. H., Gerhart, J., Freeman, R. M., Jr. and Lowe, C. J. (2014). The Fox/Forkhead transcription factor family of the hemichordate Saccoglossus kowalevskii. EvoDevo 5, 17.

García-Alonso, L., Romani, S. and Jiménez, F. (2000). The EGF and FGF receptors mediate neuroglian function to control growth cone decisions during sensory axon guidance in Drosophila. Neuron 28, 741-752.

Garner, S., Zysk, I., Byrne, G., Kramer, M., Moller, D., Taylor, V. and Burke, R. D. (2016). Neurogenesis in sea urchin embryos and the diversity of deuterostome neurogenic mechanisms. Development 143, 286-297.

Gąsiorowski, L. and Hejnol, A. (2020). Hox gene expression during development of the phoronid Phoronopsis harmeri. EvoDevo 11, 2.

Good, K., Ciosk, R., Nance, J., Neves, A., Hill, R. J. and Priess, J. R. (2004). The Tbox transcription factors TBX-37 and TBX-38 link GLP-1/Notch signaling to mesoderm induction in C. elegans embryos. Development 131, 19671978. 
Green, S. A., Norris, R. P., Terasaki, M. and Lowe, C. J. (2013). FGF signaling induces mesoderm in the hemichordate Saccoglossus kowalevskii. Development 140, 1024-1033.

Grifone, R., Demignon, J., Houbron, C., Souil, E., Niro, C., Seller, M. J., Hamard, G. and Maire, P. (2005). Six1 and Six4 homeoproteins are required for Pax3 and Mrf expression during myogenesis in the mouse embryo. Development 132, 2235-2249.

Harfe, B. D., Branda, C. S., Krause, M., Stern, M. J. and Fire, A. (1998). MyoD and the specification of muscle and non-muscle fates during postembryonic development of the C. elegans mesoderm. Development 125, 2479-2488.

Hartenstein, V., Technau, G. and Campos-Ortega, J. (1985). Fate-mapping in wild type Drosophila melanogaster III. A fate map of the blastoderm. Roux's Archiv. Dev. Biol. 194, 213-216.

Henry, J. J. and Martindale, M. Q. (1999). Conservation and innovation in spiralian development. Hydrobiologia 402, 255-265.

Hertwig, R. (1896). Lehrbuch der Zoologie. Jena: Gustav Fischer Verlag.

Hinman, V. F. and Davidson, E. H. (2007). Evolutionary plasticity of developmental gene regulatory network architecture. Proc. Natl. Acad. Sci. U. S. A. 104, 19404-19409.

Hinman, V. F. and Degnan, B. M. (2002). Mox homeobox expression in muscle lineage of the gastropod Haliotis asinina: evidence for a conserved role in bilaterian myogenesis. Dev. Genes Evol. 212, 141-144.

Hyman, L. H. (1951). The invertebrates: Platyhelminthes and Rhynchocoela, the acoelomate Bilateria. New York: McGraw-Hill; Stated First Edition edition.

Imai, K. S., Hino, K., Yagi, K., Satoh, N. and Satou, Y. (2004). Gene expression profiles of transcription factors and signaling molecules in the ascidian embryo: towards a comprehensive understanding of gene networks. Development 131, 4047-4058.

Imai, K. S., Satoh, N. and Satou, Y. (2002). Early embryonic expression of FGF4/6/9 gene and its role in the induction of mesenchyme and notochord in Ciona savignyi embryos. Development 129, 1729-1738.

Itoh, N. and Ornitz, D. M. (2004). Evolution of the Fgf and Fgfr gene families. Trends Genet. 20, 563-569.

Kadam, S., McMahon, A., Tzou, P. and Stathopoulos, A. (2009). FGF ligands in Drosophila have distinct activities required to support cell migration and differentiation. Development 136, 739-747.

Kapp, H. (2000). The unique embryology of Chaetognatha. Zool. Anz. 239, 263266.

Kim, G. J. and Nishida, H. (2001). Role of the FGF and MEK signaling pathway in the ascidian embryo. Dev. Growth Differ. 43, 521-533.

Kimelman, D. (2006). Mesoderm induction: from caps to chips. Nat. Rev. Genet. 7, 360-372.

Kocot, K. M., Struck, T. H., Merkel, J., Waits, D. S., Todt, C., Brannock, P. M., Weese, D. A., Cannon, J. T., Moroz, L. L., Lieb, B., et al. (2017). Phylogenomics of Lophotrochozoa with Consideration of Systematic Error. Syst. Biol. 66, 256-282.

Koop, D., Richards, G. S., Wanninger, A., Gunter, H. M. and Degnan, B. M. (2007). The role of MAPK signaling in patterning and establishing axial symmetry in the gastropod Haliotis asinina. Dev. Biol. 311, 200-212. 
Kowalevsky, A. 0. (1874). On the development of the Brachiopoda. In Izvestia Obshchestvo Liubiteley Estestvozaniya Anthropologii i Etnografii, pp. 1-40.

Kozin, V. and Kostyuchenko, R. (2016). Evolutionary conservation and variability of the mesoderm development in spiralia: A peculiar pattern of nereid polychaetes. Biol. Bull. 43, 216-225.

Kozin, V. V., Babakhanova, R. A. and Kostiuchenko, R. P. (2013). Functional role for MAP kinase signaling in cell lineage and dorso-ventral axis specification in the basal gastropod Testudinalia testudinalis (Patellogastropoda, Molluska). Russ. J. Dev. Biol. 44, 42-56.

Kozin, V. V., Filimonova, D. A., Kupriashova, E. E. and Kostyuchenko, R. P. (2016). Mesoderm patterning and morphogenesis in the polychaete Alitta virens (Spiralia, Annelida): Expression of mesodermal markers Twist, Mox, Evx and functional role for MAP kinase signaling. Mech. Dev. 140, 1-11.

Kozmik, Z., Holland, N. D., Kreslova, J., Oliveri, D., Schubert, M., Jonasova, K., Holland, L. Z., Pestarino, M., Benes, V. and Candiani, S. (2007). Pax-SixEya-Dach network during amphioxus development: conservation in vitro but context specificity in vivo. Dev. Biol. 306, 143-159.

Lambert, J. D. (2008). Mesoderm in spiralians: the organizer and the $4 \mathrm{~d}$ cell. J. Exp. Zool. B. Mol. Dev. Evol. 310, 15-23.

Lambert, J. D. and Nagy, L. M. (2001). MAPK signaling by the D quadrant embryonic organizer of the mollusc Ilyanassa obsoleta. Development 128, 45-56.

--- (2003). The MAPK cascade in equally cleaving spiralian embryos. Dev. Biol. 263, 231-241.

Lartillot, N., Le Gouar, M. and Adoutte, A. (2002). Expression patterns of fork head and goosecoid homologues in the mollusc Patella vulgata supports the ancestry of the anterior mesendoderm across Bilateria. Dev. Genes Evol. 212, 551-561.

Laumer, C. E., Fernandez, R., Lemer, S., Combosch, D., Kocot, K. M., Riesgo, A., Andrade, S. C. S., Sterrer, W., Sorensen, M. V. and Giribet, G. (2019). Revisiting metazoan phylogeny with genomic sampling of all phyla. Proc. $R$. Soc. B 286, 20190831.

Leptin, M. and Affolter, M. (2004). Drosophila gastrulation: identification of a missing link. Curr. biol. 14, 480-482.

Lo, T. W., Branda, C. S., Huang, P., Sasson, I. E., Goodman, S. J. and Stern, M. J. (2008). Different isoforms of the $C$. elegans FGF receptor are required for attraction and repulsion of the migrating sex myoblasts. Dev. Biol. 318, 268-275.

Lyons, D. C. and Henry, J. Q. (2014). Ins and outs of Spiralian gastrulation. Int. J. Dev. Biol. 58, 413-428.

Mahlapuu, M., Ormestad, M., Enerback, S. and Carlsson, P. (2001). The forkhead transcription factor Foxf1 is required for differentiation of extraembryonic and lateral plate mesoderm. Development 128, 155-166.

Mankoo, B. S., Collins, N. S., Ashby, P., Grigorieva, E., Pevny, L. H., Candia, A., Wright, C. V., Rigby, P. W. and Pachnis, V. (1999). Mox2 is a component of the genetic hierarchy controlling limb muscle development. Nature 400, 69-73. 
Martín-Durán, J., Passamaneck, Y. J., Martindale, M. Q. and Hejnol, A. (2016). The developmental basis for the recurrent evolution of deuterostomy and protostomy. Nat. Ecol. Evol. 1, 5.

Martin-Duran, J. M. and Hejnol, A. (2015). The study of Priapulus caudatus reveals conserved molecular patterning underlying different gut morphogenesis in the Ecdysozoa. BMC Biol. 13, 29.

Martindale, M. Q., Pang, K. and Finnerty, J. R. (2004). Investigating the origins of triploblasty: 'mesodermal' gene expression in a diploblastic animal, the sea anemone Nematostella vectensis (phylum, Cnidaria; class, Anthozoa). Development 131, 2463-2474.

Materna, S. C., Ransick, A., Li, E. and Davidson, E. H. (2013). Diversification of oral and aboral mesodermal regulatory states in pregastrular sea urchin embryos. Dev. Biol. 375, 92-104.

Mathieu, J., Griffin, K., Herbomel, P., Dickmeis, T., Strahle, U., Kimelman, D., Rosa, F. M. and Peyrieras, N. (2004). Nodal and Fgf pathways interact through a positive regulatory loop and synergize to maintain mesodermal cell populations. Development 131, 629-641.

Matus, D. Q., Copley, R. R., Dunn, C. W., Hejnol, A., Eccleston, H., Halanych, K. M., Martindale, M. Q. and Telford, M. J. (2006). Broad taxon and gene sampling indicate that chaetognaths are protostomes. Curr. Biol. 16, 575576.

Matus, D. Q., Thomsen, G. H. and Martindale, M. Q. (2007). FGF signaling in gastrulation and neural development in Nematostella vectensis, an anthozoan cnidarian. Dev. Genes Evol. 217, 137-148.

McMahon, A., Reeves, G. T., Supatto, W. and Stathopoulos, A. (2010). Mesoderm migration in Drosophila is a multi-step process requiring FGF signaling and integrin activity. Development 137, 2167-2175.

Mohammadi, M., McMahon, G., Sun, L., Tang, C., Hirth, P., Yeh, B. K., Hubbard, S. R. and Schlessinger, J. (1997). Structures of the tyrosine kinase domain of fibroblast growth factor receptor in complex with inhibitors. Science 276, 955-960.

Nederbragt, A. J., Lespinet, O., van Wageningen, S., van Loon, A. E., Adoutte, A. and Dictus, W. J. (2002). A lophotrochozoan twist gene is expressed in the ectomesoderm of the gastropod mollusk Patella vulgata. Evol. Dev. 4, 334343.

Nielsen, C. (1991). The development of the brachiopod Crania (Neocrania) anomala (of Müller) and its phylogenetic significance. Acta Zool. 72, 7-28.

Ornitz, D. M. and Itoh, N. (2015). The Fibroblast Growth Factor signaling pathway. WIRES Dev. Biol. 4, 215-266.

Osborne, C. C., Perry, K. J., Shankland, M. and Henry, J. Q. (2018). Ectomesoderm and epithelial-mesenchymal transition-related genes in spiralian development. Dev. Dyn. 247, 1097-1120.

Partanen, J., Schwartz, L. and Rossant, J. (1998). Opposite phenotypes of hypomorphic and Y766 phosphorylation site mutations reveal a function for Fgfr1 in anteroposterior patterning of mouse embryos. Genes Dev. 12, 2332-2344.

Pasini, A., Manenti, R., Rothbaecher, U. and Lemaire, P. (2012). Antagonizing retinoic acid and FGF/MAPK pathways control posterior body patterning in the invertebrate chordate Ciona intestinalis. PLoS One 7. 
Passamaneck, Y. J., Hejnol, A. and Martindale, M. Q. (2015). Mesodermal gene expression during the embryonic and larval development of the articulate brachiopod Terebratalia transversa. EvoDevo 6,10.

Perry, K. J., Lyons, D. C., Truchado-Garcia, M., Fischer, A. H., Helfrich, L. W., Johansson, K. B., Diamond, J. C., Grande, C. and Henry, J. Q. (2015). Deployment of regulatory genes during gastrulation and germ layer specification in a model spiralian mollusc Crepidula. Dev. Dyn. 244, 12151248.

Peter, I. S. (2020). The function of architecture and logic in developmental gene regulatory networks. Curr. Top. Dev. Biol. 139, 267-295.

Pfeifer, K., Schaub, C., Domsch, K., Dorresteijn, A. and Wolfstetter, G. (2014). Maternal inheritance of twist and analysis of MAPK activation in embryos of the polychaete annelid Platynereis dumerilii. PLoS One 9, e96702.

Photos, A., Gutierrez, A. and Sommer, R. J. (2006). sem-4/spalt and egl-17/FGF have a conserved role in sex myoblast specification and migration in $P$. pacificus and C. elegans. Dev. Biol. 293, 142-153.

Plenk, H. (1913). Die Entwicklung von Cistella (Argiope) neapolitana. Ein Beitrag zur Entwicklungsgeschichte der Brachiopoden (1. Mitteilung). Arb zool Inst Univ Wien 20, 93-108.

Pollak, D. D., Minh, B. Q., Cicvaric, A. and Monje, F. J. (2014). A novel Fibroblast Growth Factor Receptor family member promotes neuronal outgrowth and synaptic plasticity in Aplysia. Amino acids 46, 2477-2488.

Rattenbury, J. C. (1954). The embryology of Phoronopsis viridis. J. Morphol. 95, 289-349.

Rentzsch, F., Fritzenwanker, J. H., Scholz, C. B. and Technau, U. (2008). FGF signalling controls formation of the apical sensory organ in the cnidarian Nematostella vectensis. Development 135, 1761-1769.

Röttinger, E., Saudemont, A., Duboc, V., Besnardeau, L., McClay, D. and Lepage, T. (2008). FGF signals guide migration of mesenchymal cells, control skeletal morphogenesis and regulate gastrulation during sea urchin development. Development 135, 353-365.

Rudnicki, M. A., Schnegelsberg, P. N., Stead, R. H., Braun, T., Arnold, H. H. and Jaenisch, R. (1993). MyoD or Myf-5 is required for the formation of skeletal muscle. Cell 75, 1351-1359.

Ruppert, E. E. (1991). Introduction to the aschelminth phyla. In Microscopic Anatomy of Invertebrates, pp. 11-17. New York: John Wiley and Sons Ltd.

Sandmann, T., Girardot, C., Brehme, M., Tongprasit, W., Stolc, V. and Furlong, E. E. (2007). A core transcriptional network for early mesoderm development in Drosophila melanogaster. Genes Dev. 21, 436-449.

Santagata, S., Resh, C., Hejnol, A., Martindale, M. Q. and Passamaneck, Y. J. (2012). Development of the larval anterior neurogenic domains of Terebratalia transversa (Brachiopoda) provides insights into the diversification of larval apical organs and the spiralian nervous system. EvoDevo 3, 3.

Schiemann, S. M., Martin-Duran, J. M., Borve, A., Vellutini, B. C., Passamaneck, Y. J. and Hejnol, A. (2017). Clustered brachiopod Hox genes are not expressed collinearly and are associated with lophotrochozoan novelties. Proc. Natl. Acad. Sci. U S A 114, E1913-E1922. 
Schubert, M., Meulemans, D., Bronner-Fraser, M., Holland, L. Z. and Holland, N. D. (2003). Differential mesodermal expression of two amphioxus MyoD family members (AmphiMRF1 and AmphiMRF2). Gene Expr. Patterns 3, 199-202.

Seipel, K. and Schmid, V. (2005). Evolution of striated muscle: jellyfish and the origin of triploblasty. Dev. Biol. 282, 14-26.

Shimeld, S. M., Boyle, M. J., Brunet, T., Luke, G. N. and Seaver, E. C. (2010). Clustered Fox genes in lophotrochozoans and the evolution of the bilaterian Fox gene cluster. Dev. Biol. 340, 234-248.

Stathopoulos, A., Tam, B., Ronshaugen, M., Frasch, M. and Levine, M. (2004). pyramus and thisbe: FGF genes that pattern the mesoderm of Drosophila embryos. Genes Dev. 18, 687-699.

Steinmetz, P. R. H. (2006). Comparative molecular and morphogenetic characterisation of larval body regions in the polychaete annelid Platynereis dumerilii. In Biologie: Philipps-Universität Marburg.

Sulston, J. E., Schierenberg, E., White, J. G. and Thomson, J. N. (1983). The embryonic cell lineage of the nematode Caenorhabditis elegans. Dev. Biol. 100, 64-119.

Sun, J. and Stathopoulos, A. (2018). FGF controls epithelial-mesenchymal transitions during gastrulation by regulating cell division and apicobasal polarity. Development 145.

Sweet, H. C., Hodor, P. G. and Ettensohn, C. A. (1999). The role of micromere signaling in Notch activation and mesoderm specification during sea urchin embryogenesis. Development 126, 5255-5265.

Technau, U. and Scholz, C. B. (2003). Origin and evolution of endoderm and mesoderm. Int. J. Dev. Biol. 47, 531-539.

Temereva, E. N. and Malakhov, V. V. (2007). Embryogenesis and larval development of Phoronopsis harmeri Pixell, 1912 (Phoronida): dual origin of the coelomic mesoderm. Invert. Rep.Dev. 50, 57-66.

Temereva, E. N. and Tsitrin, E. B. (2013). Development, organization, and remodeling of phoronid muscles from embryo to metamorphosis (Lophotrochozoa: Phoronida). BMC Dev. Biol. 13, 14.

True, J. R. and Haag, E. S. (2001). Developmental system drift and flexibility in evolutionary trajectories. Evol. Dev. 3, 109-119.

Vellutini, B. C. and Hejnol, A. (2016). Expression of segment polarity genes in brachiopods supports a non-segmental ancestral role of engrailed for bilaterians. Sci. Rep. 6, 32387.

Vellutini, B. C., Martín-Durán, J. M. and Hejnol, A. (2017). Cleavage modification did not alter blastomere fates during bryozoan evolution. BMC Biol. 15, 33.

Wijesena, N., Simmons, D. K. and Martindale, M. Q. (2017). Antagonistic BMPcWNT signaling in the cnidarian Nematostella vectensis reveals insight into the evolution of mesoderm. Proc. Natl. Acad. Sci. U S A 114, E5608-E5615.

Wilson, R., Vogelsang, E. and Leptin, M. (2005). FGF signalling and the mechanism of mesoderm spreading in Drosophila embryos. Development 132, 491-501.

Winnier, G., Blessing, M., Labosky, P. A. and Hogan, B. L. (1995). Bone morphogenetic protein-4 is required for mesoderm formation and patterning in the mouse. Genes Dev. 9, 2105-2116. 
Yamaguchi, T. P., Harpal, K., Henkemeyer, M. and Rossant, J. (1994). fgfr-1 is required for embryonic growth and mesodermal patterning during mouse gastrulation. Genes Dev. 8, 3032-3044.

Yasuo, H. and Hudson, C. (2007). FGF8/17/18 functions together with FGF9/16/20 during formation of the notochord in Ciona embryos. Dev. Biol. 302, 92-103.

Zaffran, S., Kuchler, A., Lee, H. H. and Frasch, M. (2001). biniou (FoxF), a central component in a regulatory network controlling visceral mesoderm development and midgut morphogenesis in Drosophila. Genes Dev. 15, 2900-2915.

Zimmer, R. L. (1997). Phoronids, Brachiopods, and Bryozoans, the Lophophorates In Embryology: constructing the organism (ed. S. F. Gilbert \& A. M. Raunio). Sunderland, MA, U.S.A.: Sinauer Associates, Inc. 